\title{
Histopathological Evidence of the Efficacy of Percutaneous Ethanol Injection in the Treatment of Axillary Osmidrosis: A Promising New Procedure
}

\author{
Ali Asilian $^{\text {a }}$ Bahareh Abtahi-Naeini $^{\text {b }}$ Masoom Shahbazi ${ }^{a}$ \\ ${ }^{a}$ Department of Dermatology, Isfahan University of Medical Sciences, and b ${ }^{b}$ Skin Diseases and Leishmaniasis \\ Research Center, Isfahan University of Medical Sciences, Isfahan, Iran
}

\section{Established Facts}

- Axillary osmidrosis (AO) is a common disease.

- The clinical approach to AO remains controversial, ranging from conservative medical to surgical choices.

\section{Novel Insights}

- We report the clinical and histopathological evidence of the efficacy of percutaneous ethanol injection in the treatment of $\mathrm{AO}$.

\section{Keywords}

Osmidrosis · Ethanol · Histopathology

\section{Abstract}

Axillary osmidrosis (AO) is a common disease, affecting patients psychologically and influencing their quality of life. The medical approach to AO remains controversial, ranging from conservative medical to surgical choices. We describe the successful treatment of $A O$ and axillary hyperhidrosis $(A H)$ using percutaneous ethanol injection (PEI) in a 30-year-old patient with $\mathrm{AO}$ and $\mathrm{AH}$ who did not respond to topical and systemic medication. We also describe the clinical efficacy of PEI by presenting our experience with histopathological evidence of necrosis of the sweat glands.

(c) 2017 S. Karger AG, Basel

\section{Introduction}

Axillary osmidrosis ( $\mathrm{AO}$ ) is characterized by an unpleasant odor that originates from the apocrine glands in the axillary area, and axillary hyperhidrosis $(\mathrm{AH})$ is defined as excessive sweating $[1,2]$. Both of them are common diseases in dermatology. The two diseases affect patients psychologically and influence their quality of life $[1,2]$. To date, some strategies for the treatment of $\mathrm{AO}$ and $\mathrm{AH}$ have been developed, with variable efficacy [3]. $\mathrm{A}$ major concern about the treatment of $\mathrm{AO}$ and $\mathrm{AH}$ is the lack of clinical guidelines [3]. Overall, in the current literature, the clinical approach to $\mathrm{AO}$ and $\mathrm{AH}$ remains controversial, ranging from conservative medical to surgical choices [4].

\section{KARGER}

(c) 2017 S. Karger AG, Basel

E-Mail karger@karger.com

www.karger.com/sad
Dr. Masoom Shahbazi

Department of Dermatology, Al-Zahra Hospital, Soffe Blvd.

Isfahan University of Medical Sciences

Isfahan (Iran)

E-Mail masoom_sh1982@yahoo.com 

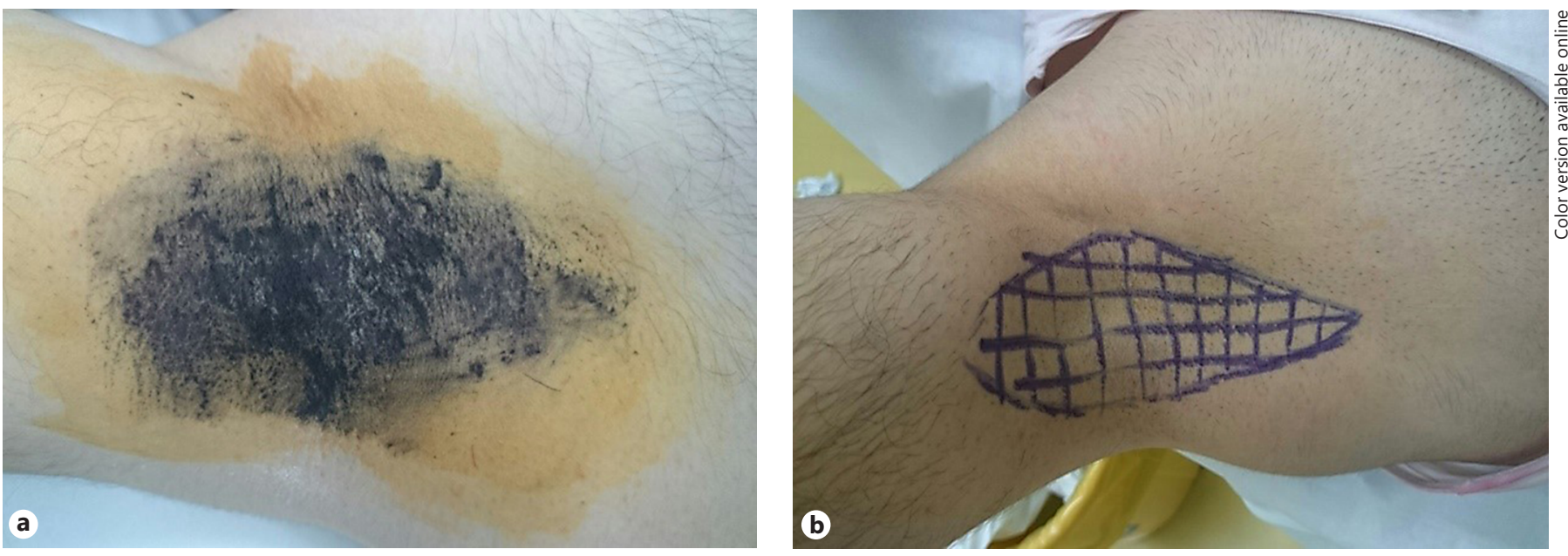

Fig. 1. The procedure was performed in four steps. Step 1: starch-iodine test (a). Step 2: marking the area to be treated (b). Step 3: injecting the local anesthetic. Step 4: injecting ethanol.
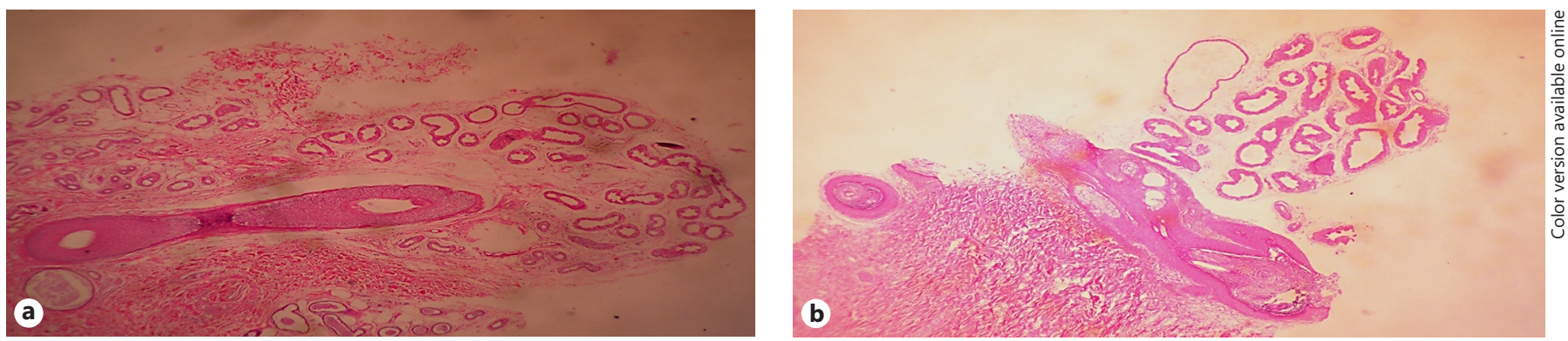

Fig. 2. Comparison of pre- (a) and postprocedure (b) histopathology shows a reduction in the number of both normal apocrine and eccrine glands after treatment.

Evidence shows that percutaneous ethanol injection (PEI) can play an important role in the treatment of some of specific carcinomas, include thyroid carcinoma [5].

The goal of surgical procedures is to reduce or eliminate the sweat glands. PEI is a procedure that attempts to chemically destroy and eliminate the skin appendages [6].

We describe the patient's clinical data and outcome as well as the details of the PEI procedure. We also discuss the efficacy of PEI by presenting our experience with histopathological evidence of necrosis of the sweat glands and their relation to PEI in the treatment of $\mathrm{AO}$ and $\mathrm{AH}$.

\section{Case Report}

A 30-year-old patient who did not respond to topical and systemic medication, but met the criteria for bilateral $\mathrm{AO}$ and $\mathrm{AH}$ and was suitable for surgery, was treated in 2016 at the Department of Dermatology of our institute.

Ethanol Injection for Osmidrosis
The patient had received treatments with various external preparations, including antiperspirants or deodorants and oral anticholinergic medication for approximately 3 years. All these treatments had, however, been ineffective. He also refused to continue treatment with botulinum toxin A due to transient effect.

The patient was suitable for surgical intervention including removal of the subcutaneous tissue, liposuction, and endoscopic thoracic sympathectomy, but he did not accept these options due to possible complications. Thus, PEI was attempted.

The patient was placed in the supine position with his arms abducted to about $100^{\circ}$. The axillary hair was shaved before surgery, and the axillary hairline and $1 \mathrm{~cm}$ beyond the outline were marked on both sides after the starch-iodine test. To reduce the uneven distribution of medications, a grid pattern composed of squares of $1 \mathrm{~cm}^{2}$ was drawn on the preoperative bilateral axillae (Fig. 1).

After standard sterilization of the axillary area, a $30-\mathrm{mL}$ mixture of $2 \%$ lidocaine (Pasteur Institute, Iran) with normal saline ( $0.9 \%$ sodium chloride; PLC, Tehran, Iran) to provide a $0.25 \%$ concentration was injected on each side of the superficial and deep subcutaneous layer (Fig. 1). Next, $1 \mathrm{~mL}$ of $90 \%$ sterile ethanol per $1 \mathrm{~cm}^{3}$ of tissue was injected at the dermal-subdermal junction us- 

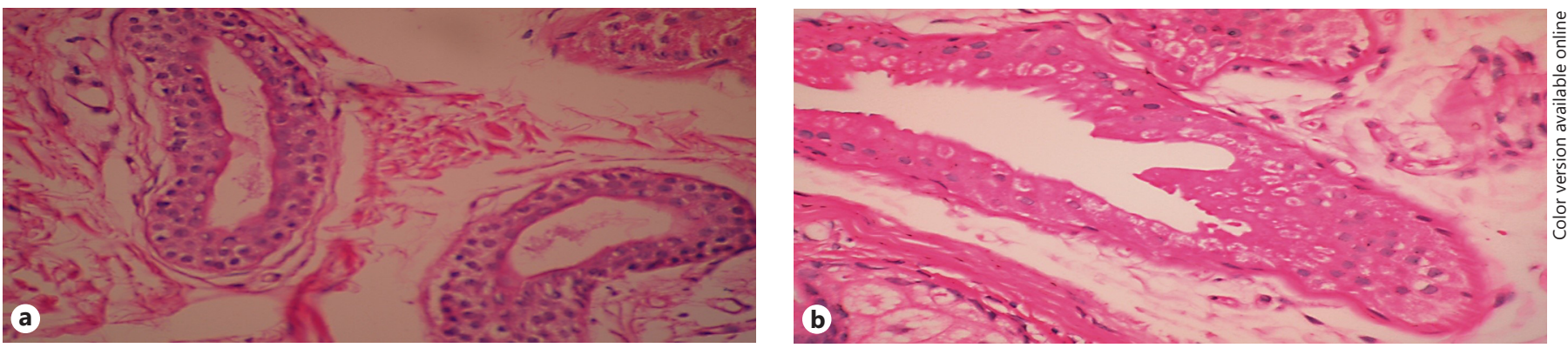

Fig. 3. Pre- and postprocedure histopathology. a Normal appearance of the sweat glands before treatment. $\mathbf{b}$ The luminal cells had lost their nuclei, which was consistent with a degenerative process; most of the myoepithelial cells looked normal, showing the beginning of a necrotic process.

ing a 30-gauge needle. The volume of the ethanol was calculated using half the length of the axilla in half the width of axilla in the thickness of axilla, which was approximately $3 \mathrm{~mm}$. This patient was injected with a volume of about $12 \mathrm{~mL}$ of ethanol.

The total procedure time was about $60 \mathrm{~min}$. Immediately after treatment, cold bags were applied for about 5-10 min to minimize postoperative edema or discomfort. Postoperatively, a small dressing was applied for 2-3 days.

After the treatment, we followed our patient on postprocedure days $1,3,30$, and 300 . Pre- and postprocedure 4-mm punch biopsies at the center of the axilla were obtained in one axilla. Postprocedure biopsy was done 1 month after the procedure. Preprocedure slides showed an increased number of apocrine glands. On microscopic examination of the axilla post treatment, there was a reduction in the number of both apocrine and eccrine glands (Fig. 2).

The luminal cells had lost their nuclei, which was consistent with a degenerative process of apocrine and eccrine glands. Most of the myoepithelial cells looked normal, showing the beginning of a necrotic process (Fig. 3). Most of the sweat glands in the subcutaneous layer and deep dermis had been destroyed by the procedure, and only the epidermis and superficial dermis were intact. The patient exhibited no relapse of $\mathrm{AO}$ and $\mathrm{AH} 3,6,12$, and 18 months after the procedure.

\section{Discussion}

$\mathrm{AH}$ in the form of excessive sweeting is sometimes accompanied by $\mathrm{AO}$ as malodorous sweating; both conditions lead to a subjective reduction in quality of life for the patient, who feels uncomfortable in the world. Many treatment options, especially destructive method, are the same for both conditions [2,3].

On the one hand, medical treatments such as topical agents, systemic agents, and botulinum toxin A have temporary results in the treatment of $\mathrm{AO}[3,7]$. Most patients seek a more permanent solution, which can be accomplished only by more invasive means. On the other hand, surgical treatments with relatively permanent effects include removal of the subcutaneous tissue, liposuction, and endoscopic thoracic sympathectomy treatment, but they are invasive and usually have risk for complications $[1,8$, 9]. Meanwhile, a therapeutic procedure that is effective, safe, and permanent is still needed. The result of our case corresponds with previous results showing that destruction of apocrine and eccrine glands can improve $\mathrm{AO}$ and $\mathrm{AH}$ [10]. This limited study clinically evaluated the use of PEI in the treatment of $\mathrm{AO}$ and suggests that PEI is effective [6].

In the study of Han and Li [6], after injection of $90 \%$ PEI into the subcutaneous layer (average amount of ethanol injected per side $8.9 \mathrm{~mL}$, mean follow-up period 14.5 months), the majority of patients had excellent to good results and considered themselves satisfied (92.1\%). All procedure-related complications were mild to moderate and healed without sequels. However, there are no published data on histological confirmation of successful treatment.

Though a new technique, PEI, shows positive effects on the histological pattern of affected skin after treatment and can be used as an effective method for the treatment of $\mathrm{AO}$, further studies are needed to confirm and clearly define the histopathological changes induced in the skin by ethanol.

\section{Statement of Ethics}

The patient gave written informed consent before treatment.

\section{Disclosure Statement}

The authors report no conflicts of interest. They alone are responsible for the content and writing of this paper. 


\section{References}

1 Kim D, Kim J, Yeo H, Kwon H, Son D, Han $\mathrm{K}$ : Treatment of axillary osmidrosis using a subcutaneous pulsed Nd-YAG laser. Arch Plast Surg 2012;39:143-149.

2 Abtahi-Naeini B, Naeini FF, Adibi N, Pourazizi M: Quality of life in patients with primary axillary hyperhidrosis before and after treatment with fractionated microneedle radiofrequency. J Res Med Sci 2015;20:631-635.

3 Shin JY, Roh SG, Lee NH, Yang KM: Osmidrosis treatment approaches: a systematic review and meta-analysis. Ann Plast Surg 2017; 78:354-359.
4 Lee SG, Ryu HJ, Kim IH: Minimally invasive surgery for axillary osmidrosis using a combination of subcutaneous tissue removal and a 1,444-nm Nd:YAG laser. Ann Dermatol 2014; 26:755-757.

5 Perez CL, Fighera TM, Miasaki F, Mesa Junior CO, Paz Filho GJ, Graf H, Carvalho GA: Evaluation of percutaneous ethanol injections in benign thyroid nodules. Arq Bras Endocrinol Metabol 2014;58:912-917.

6 Han X, Li F: Percutaneous ethanol injection for the treatment of axillary osmidrosis. Clin Exp Dermatol 2013;38:484-488.

7 Xie A, Nie L, Tan Q: Local injection of botulinum toxin A: an alternative therapy for axillary osmidrosis. J Dermatol 2014;41:153-156.
8 Wang C, Wu H, Du F, Le S, Zheng S: Axillary osmidrosis treatment using an aggressive suction-curettage technique: a clinical study on paired control. Aesthetic Plast Surg 2015;39: 608-615.

9 Rezende RM, Luz FB: Surgical treatment of axillary hyperhidrosis by suction-curettage of sweat glands. An Bras Dermatol 2014;89:940 954.

10 Naeini FF, Saffaei A, Pourazizi M, AbtahiNaeini B: Histopathological evidence of efficacy of microneedle radiofrequency for treatment of axillary hyperhidrosis. Indian J Dermatol Venereol Leprol 2015;81:288-290. 